\title{
Enhanced Sensitivity and Detection of Near-Infrared Refractive Index Sensor with Plasmonic Multilayers
}

\author{
Tan Tai Nguyen ${ }^{1, * \mathbb{D}}$, Nguyen Van Sau ${ }^{2}$, Quang Minh Ngo ${ }^{3,4,5} \mathbb{D}$, Gauthier Eppe ${ }^{6} \mathbb{D}$, Ngoc Quyen Tran ${ }^{7,8}$ \\ and Nguyen Thi Phuong Anh 9
}

1 Department of Materials Science, School of Applied Chemistry, Tra Vinh University, Tra Vinh City 87000, Vietnam

2 School of Basic Science, Tra Vinh University, Tra Vinh City 87000, Vietnam; nvsau@tvu.edu.vn

3 Vietnam Academy of Science and Technology, University of Science and Technology of Hanoi, Hanoi 100000, Vietnam; ngo-quang.minh@usth.edu.vn

4 Institute of Materials Science, Vietnam Academy of Science and Technology, Hanoi 100000, Vietnam

5 Graduate University of Science and Technology, Vietnam Academy of Science and Technology, Hanoi 100000, Vietnam

6 Mass Spectrometry Laboratory, MolSys RU, Department of Chemistry, University of Liège, Allée du Six Août, 11-Quartier Agora, 4000 Liège, Belgium; g.eppe@uliege.be

7 Graduate University of Science and Technology, Vietnam Academy of Science and Technology, Ho Chi Minh City 700000, Vietnam; tnquyen979@gmail.com

8 Institute of Applied Materials Science, Vietnam Academy of Science and Technology, Ho Chi Minh City 700000, Vietnam

9 Faculty of Chemical Engineering, Ho Chi Minh City University of Technology, Ho Chi Minh City 700000, Vietnam; ntpanh369@gmail.com

check for updates

Citation: Nguyen, T.T.; Van Sau, N.; Ngo, Q.M.; Eppe, G.; Tran, N.Q.; Thi Phuong Anh, N. Enhanced Sensitivity and Detection of Near-Infrared Refractive Index Sensor with Plasmonic Multilayers. Sensors 2021, 21,7056. https://doi.org/10.3390/ s21217056

Academic Editor: Ali Passian

Received: 2 September 2021

Accepted: 19 October 2021

Published: 25 October 2021

Publisher's Note: MDPI stays neutral with regard to jurisdictional claims in published maps and institutional affiliations.

Copyright: (c) 2021 by the authors. Licensee MDPI, Basel, Switzerland. This article is an open access article distributed under the terms and conditions of the Creative Commons Attribution (CC BY) license (https:/ / creativecommons.org/licenses/by/ $4.0 /)$.
* Correspondence: nttai60@tvu.edu.vn

\begin{abstract}
In this work, the multilayer of the surface plasmon resonance (SPR) sensor was optimized to achieve the maximum sensor sensitivity. By optimizing the thickness of the silver layer (Ag) and dielectric films ( $\mathrm{TiO}_{2}$ and AlAs), the optimum sensitivity of the SPR sensor could be obtained. The performance of the SPR sensor proposed was compared with control simulations utilizing zinc oxide $(\mathrm{ZnO})$ and molybdenum oxide $\left(\mathrm{MoO}_{3}\right)$. The numerical results indicate that the figure-of-merits (FOM) of the SPR sensor was achieved around 150/RIU, corresponding to the sensor sensitivity of $162.79^{\circ} / \mathrm{RIU}$ with the optimized thicknesses of the $\mathrm{TiO}_{2}, \mathrm{Ag}$, and AlAs layers of $140 \mathrm{~nm}, 60 \mathrm{~nm}$, and $25 \mathrm{~nm}$, respectively. This refractive index sensor shows the FOM to have high detection accuracy and high sensitivity that lead to finding potential application in bio-chemical detection with a small volume of liquid used in biological diagnosis.
\end{abstract}

Keywords: combination; multilayer; infrared laser; sensor; surface plasmon resonance

\section{Introduction}

Over the last few decades, the optical detection technique has been widely used for biochemical applications for the study of biological binding and recognition [1-4]. Most studies have been focused on the development of the surface plasmon resonance (SPR) sensor. Typical SPR sensors have been implemented based on the Kretschmann configuration with a thin metal layer deposited on the prism [5-9] or optical fiber [10-15]. The change in the refractive index on the sensor surface can be indirectly recognized by measuring the wavelength or the angle at which the SPR condition is justified. In the reflected curve, the depth-to-width ratio and the change in wavelength or angle over the change in the refractive index demonstrate the figure-of-merits (FOM) of the SPR wave. Consequently, this SPR sensor structure is mainly applied for biomedical applications, i.e., the detection of fibrinogen for early disease diagnosis [16-19], glucose detection [20,21], foodborne bacterial pathogens detection [22-25], biotin-streptavidin binding [26], the detection of low-molecular-weight $(<500 \mathrm{Da})$ biomolecules [27], and the detection of 
polypeptides [28]. It is noted that the SPR sensor with a multi-metal combination has shown a great benefit in terms of FOM. However, those configurations have relatively inherent drawbacks due to the strong energy of the visible light, which could damage the target biomolecules. To overcome this limitation, the use of infrared (IR) laser is a promising and attractive technique. Recently, the great benefit of SPR sensors utilizing IR laser has been reported [29-32].

The choice of metal layer for the surface is needed for optimizing the FOM of the sensor. Typically, gold (Au) and silver (Ag) are commonly used for SPR sensing platforms. The use of $\mathrm{Au}$ is widely adopted for the sensor surface due to its chemical stability $[6,33,34]$. However, the Au-coated SPR sensor is quite expensive. Alternatively, another promising material for SPR sensors is Ag, which has offered high sensitivity. However, Ag can easily oxidize $[35,36]$. In addition, dielectric materials (i.e., titanium dioxide $\left(\mathrm{TiO}_{2}\right)$, molybdenum oxide $\left(\mathrm{MoO}_{3}\right)$, and zinc oxide $\left.(\mathrm{ZnO})\right)$ have offered great benefits for the enhancement of sensor sensitivity by combining them with plasmonic materials [37-39]. Those materials have numerous advantages due to their smaller real permittivity magnitude than metals [37-39]. Recently, $\mathrm{MoO}_{3}$ has been utilized for a chemo-resistive sensor for the selective monitoring of $\mathrm{H}_{2}$ [38]. Moreover, portable optical sensors are also interesting for next-generation computing based on edge computing [40]. This leads to the investigation of a new SPR sensing platform based on a multilayer structure at a lower frequency range.

This work aims to enhance the sensor's FOM with a new SPR structure based on a prism with a three-layer combination, comprising $\mathrm{TiO}_{2} / \mathrm{Ag} /$ aluminum arsenide (AlAs)/sensing medium for foodborne bacterial detection. The theoretical modeling and analysis are also presented with a detailed description. The design structure is optimized based on different modulation thicknesses of $\mathrm{Ag}$ layer and dielectric materials $\left(\mathrm{TiO}_{2}\right.$ and $\mathrm{AlAs}$ ), with a refractive index of sensing in the medium range of 1.33-1.351 (RIU). The change in refractive index corresponds to an $E$. coli concentration of $10^{3} \mathrm{cfu} / \mathrm{mL}$ [41]. Furthermore, the performance of the SPR sensor was compared with the established SPR configurations $\left(\mathrm{ZnO}\right.$ and $\left.\mathrm{MoO}_{3}\right)$. The results show that the SPR sensor performance with a wavelength of $1064 \mathrm{~nm}$ exhibited an enhancement of the FOM, i.e., sensitivity and detection accuracy for the combination structure of prism $/ \mathrm{TiO}_{2} / \mathrm{Ag} / \mathrm{AlAs}$.

\section{Materials and Methods}

A BK7 prism was utilized for the design of the optical sensor, which is depicted in Figure 1. The multilayer structure proposed comprises prism/ $/ \mathrm{TiO}_{2} / \mathrm{Ag} / \mathrm{AlAs}$ with the semiconductor layer exposed to sensing mediums of varying refractive indices. The additional layer of $\mathrm{TiO}_{2}$ enhanced the adhesion between the plasmonic $\mathrm{Ag}$ layer and the prism and achieved high efficiency in light trapping for plasmonic excitation [37]. In addition, an enhanced SPR detection was achieved by incorporating an AlAs layer on top of a thin Ag film [42-44]. This is an effective alternative in bypassing the oxidation of an Ag layer [45]. It should be noted that those materials can be deposited on the prism (BK7) by using a thermal evaporation system or a magnetron sputtering technique [12,46].

For excitation of the surface plasmon wave, a collimated beam of IR laser with a wavelength of $1064 \mathrm{~nm}$ was incident to the prism surface by passing through a polarizer to obtain the transverse magnetic (TM) polarization light. To perform the simulation for the multilayer optical sensor, the simulated parameters are given in Table 1.

Table 1. Parameters of materials used for simulation.

\begin{tabular}{cccc}
\hline Materials & Wavelength $(\mathbf{n m})$ & Dielectric Constant $\left(\varepsilon_{\mathbf{r}}+\mathbf{i} \varepsilon_{\mathbf{i}}\right)$ & References \\
\hline Prism (BK7) & 1064 & 2.28 & {$[33]$} \\
\hline Ag & 1064 & $-66.26+5.83 i$ & {$[47]$} \\
\hline AlAs & 1064 & 8.64 & {$[48]$} \\
\hline
\end{tabular}


Table 1. Cont.

\begin{tabular}{cccc}
\hline Materials & Wavelength $(\mathbf{n m})$ & Dielectric Constant $\left(\varepsilon_{\mathbf{r}}+\mathbf{i} \varepsilon_{\mathbf{i}}\right)$ & References \\
\hline $\mathrm{TiO}_{2}$ & 1064 & 6.15 & {$[49]$} \\
\hline $\mathrm{ZnO}$ & 1064 & 3.76 & {$[50]$} \\
\hline $\mathrm{MoO}_{3}$ & 1064 & $4.33+0.011 \mathrm{i}$ & {$[51]$} \\
\hline
\end{tabular}

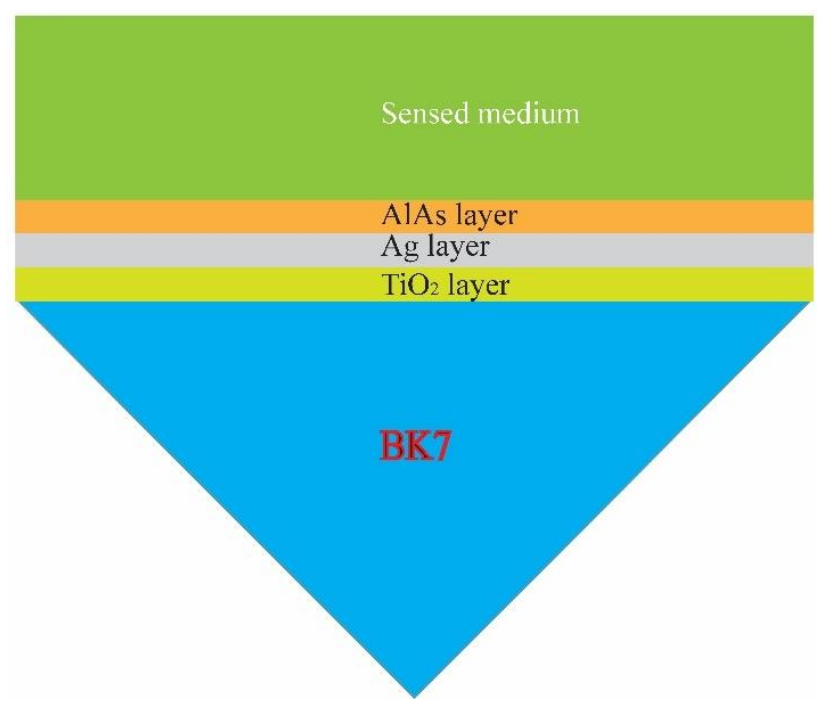

Figure 1. Sketch of the proposed sensor comprising the stacked layers of prism/ $\mathrm{TiO}_{2} / \mathrm{Ag} / \mathrm{AlAs}$.

The transfer matrix regression method was utilized to evaluate the reflection coefficient for the multilayer model of the sensor structure. In this model, the relationship between tangential field components at the first and the last interfaces is given below $[52,53]$

$$
\left[\begin{array}{c}
E_{t 1} \\
H_{t 1}
\end{array}\right]=M\left[\begin{array}{c}
E_{t 3} \\
H_{t 3}
\end{array}\right]
$$

where $E_{t 1}$ and $H_{t 1}$ are the electric and magnetic field components at the first interface $\left(\mathrm{TiO}_{2} / \mathrm{Ag}\right)$. Similarly, $E_{t 3}$ and $H_{t 3}$ are the electric and magnetic field components at the third interface (AlAs/sensing medium). In addition, $M$ is the characteristic matrix of the $N$-layer combination, as given below

$$
M=\prod_{k=2}^{N-1} M_{k}=\left[\begin{array}{ll}
M_{11} & M_{12} \\
M_{21} & M_{22}
\end{array}\right]
$$

where

$$
\begin{gathered}
M_{k}=\left[\begin{array}{cc}
\cos \beta_{k} & \left(-i / q_{k}\right) \sin \beta_{k} \\
-i q_{k} \sin \beta_{k} & \cos \beta_{k}
\end{array}\right] \\
q_{k}=\frac{\left(\varepsilon_{k}-\varepsilon_{B K 7} \sin ^{2} \varphi\right)^{1 / 2}}{\varepsilon_{k}} \\
\beta_{k}=\frac{2 \pi d_{k}}{\lambda}\left(\varepsilon_{k}-\varepsilon_{B K 7} \sin ^{2} \varphi\right)^{1 / 2}
\end{gathered}
$$

The reflection coefficient of TM field (p-polarization) and its amplitude are given below, respectively,

$$
r_{q}=\frac{\left(M_{11}+M_{12} q_{s}\right)+q_{B K 7}-\left(M_{21}+M_{22} q_{s}\right)}{\left(M_{11}+M_{12} q_{s}\right)+q_{B K 7}+\left(M_{21}+M_{22} q_{s}\right)}
$$




$$
R=\left|r_{p}\right|^{2}
$$

where $k$ is denoted for the $k$ th layer; $d_{k}$ is the thickness of the $k^{\text {th }}$ layer; $\varepsilon_{B K 7}$ is the dielectric constant of the prism used; $\varepsilon_{k}$ is the dielectric constant of the $k^{\text {th }}$-layer; $\varphi$ is the incident angle of the laser light; $\lambda$ is the wavelength of the laser; and $\varepsilon_{s}$ is the dielectric constant of the sensing medium.

After the laser light was reflected from the sensor surface, the SPR characterization was investigated based on the reflectance versus the incident angle. The resonant angle corresponded to the minimum reflectance. The resonant angle and the minimum reflectance depended on the excitation wavelength, the thicknesses of the metal (Ag), semiconductor (AlAs), and dielectric $\left(\mathrm{TiO}_{2}\right)$ layers, and the refractive index of the sensing medium (water). The thickness of all layers, including $\mathrm{Ag}$, $\mathrm{AlAs}$, and $\mathrm{TiO}_{2}$, were investigated for optimizing the sensor structure under the change in refractive index of the sensing medium. In this work, the sensor sensitivity was estimated based on the ratio between the change in the resonant angle $(\Delta \varphi)$ of the reflection curve and the change in the refractive index of the sensing medium $(\Delta n)$. From the simulated results concerning the reflectance as a function of incident angle, we estimated the sensor sensitivity, detection accuracy, and FOM as given below,

$$
\begin{gathered}
S=\frac{\Delta \varphi}{\Delta n} \\
D L=\frac{1}{F W H M} \\
F O M=S \times D L
\end{gathered}
$$

where $S$ is the sensor sensitivity and $n$ is the refractive index of the sensing medium; $D L$ is the detection accuracy and FWHM is the full-width at haft-maximum.

\section{Results and Discussion}

Most recent studies have focused on the optimization of the metal layer thickness, and it was demonstrated that the thickness of the metal layer strongly depends on the sensor structure. In the present study, the thickness of the Ag layer was optimized in the range from 30 to $70 \mathrm{~nm}$ with an increment of $10 \mathrm{~nm}$, under the excitation of the IR laser with a wavelength of $1064 \mathrm{~nm}$. Figure 2 presents the SPR characterization curve, considering that the BK7 prism was coated with a thin layer of $\mathrm{Ag}$ and covered by distilled water with a refractive index of 1.33 (RIU). In Figure $2 b$, it is observed that the resonant angle slightly shifted due to a change in the thickness of the metal layer. Moreover, the reflectivity of the SPR curve changes due to a change in the thickness of the Ag layer. The optimization thickness of the Ag layer was considered based on the reflectivity, with a minimum value or reflectance towards zero at the resonant angle at which most electromagnetic wave energy transfers to the surface plasmon wave.

Figure 3a shows the estimation of the reflectivity strength based on the SPR characteristic curve. It indicates that the optimum thickness of $\mathrm{Ag}$ is around $60 \mathrm{~nm}$ at the resonant angle of $63.5^{\circ}$ (Figure $2 \mathrm{~b}$ ). It is worth mentioning that the sensor sensitivity is also one of the factors used for considering the optimization thickness of the Ag layer. In the present case, the refractive index of the sensing medium was set from 1.33-1.351 (RIU), corresponding to the change from DI water to an $E$. coli concentration of $10^{3} \mathrm{cfu} / \mathrm{mL}$ [38]. The sensitivity of $92.1^{\circ}$ / RIU was obtained for the sensor structure comprising prism/Ag (Figure 3b). Note that the sensor sensitivity was estimated based on the change in the resonant angle over the change in the refractive index of the sensing medium. 

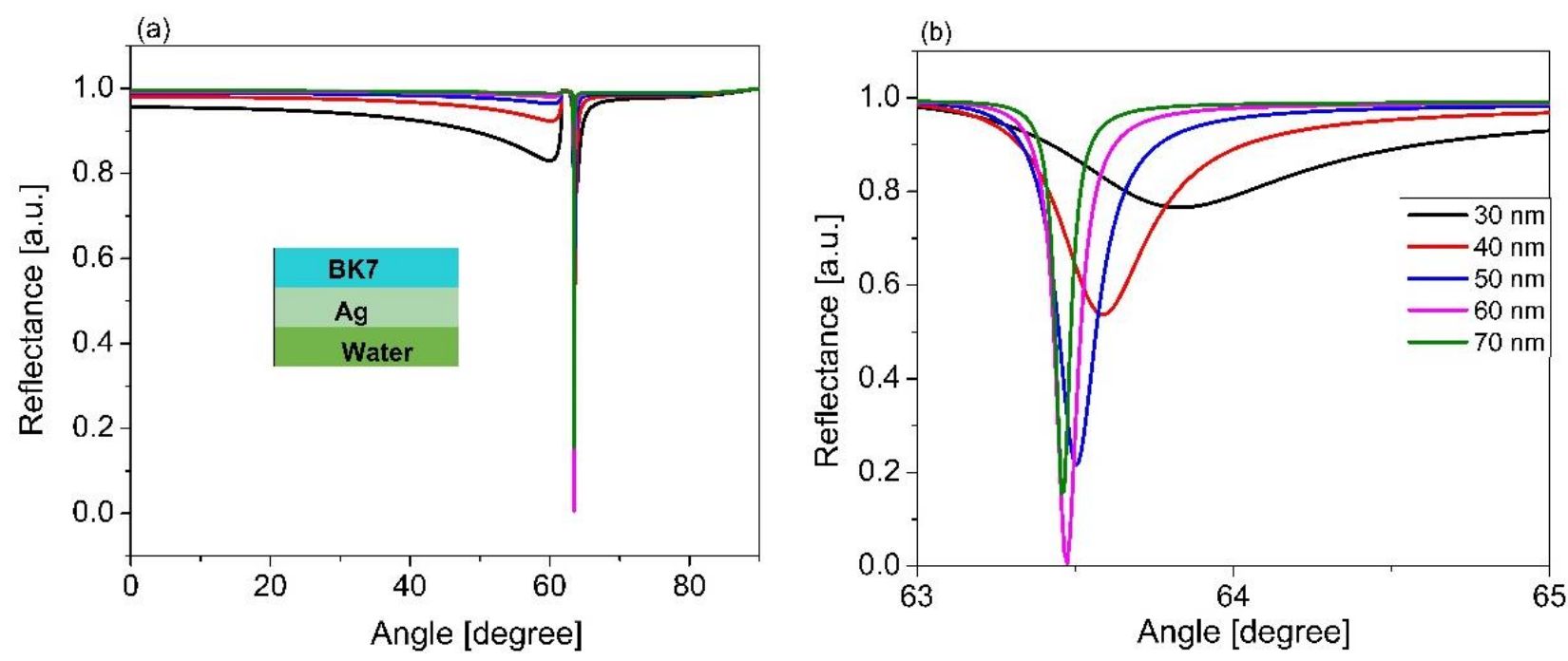

Figure 2. (a) Simulated results of Ag thickness from $30 \mathrm{~nm}$ to $70 \mathrm{~nm}$; (b) magnified view of (a) from 63 to 65 degrees.

(a)

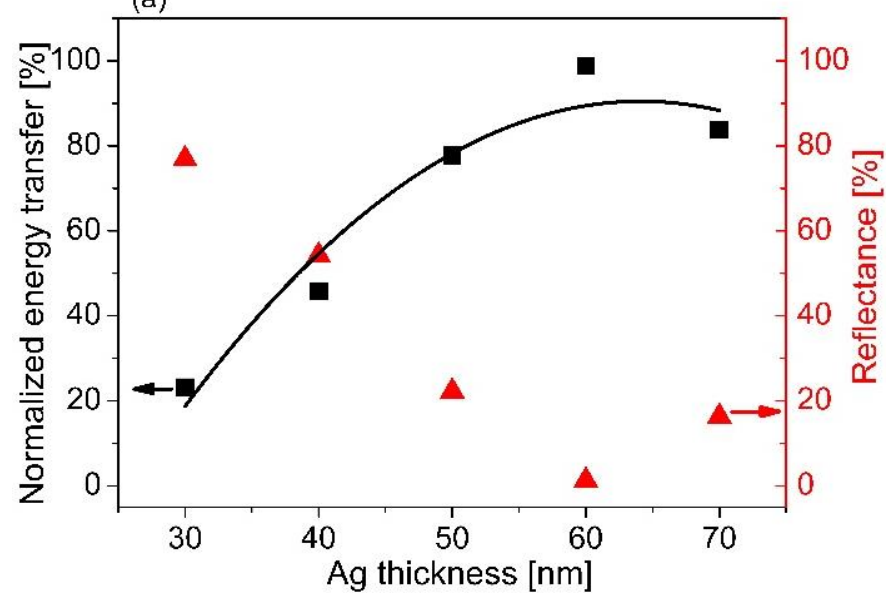

(b)

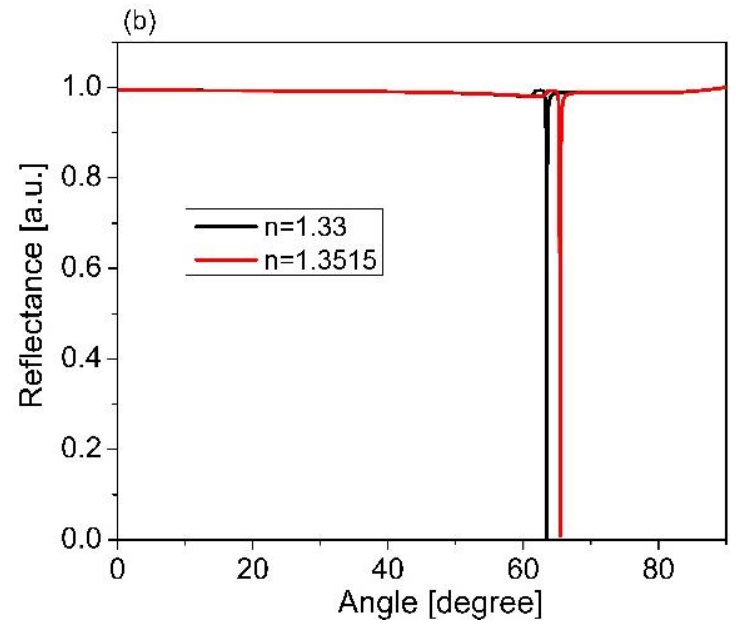

Figure 3. (a) The relationship between energy transfer and reflectance. (b) The change in resonance for different RI of the sensing medium.

To find an ideal characteristic shape for energy transfer based on the thickness of the Ag layer's change, we used the parabolic curve with a quadratic second-order equation $E_{T}=\alpha t_{A g}{ }^{2}+\beta t_{A g}-E_{o}$ to fit the simulated data in Figure 3a. The fitting results show that the minimum energy transfer $\left(E_{o}\right)$ was estimated at around 163.22 (a.u.), as shown in Table 2. The optimized thickness of Ag was obtained at $60 \mathrm{~nm}$ thickness with the resonant angle of $63.4^{\circ}$ (Figure $3 \mathrm{~b}$ ), corresponding to a maximum energy transfer of 799.78 (a.u.). Moreover, the correlation coefficients $\left(R^{2}\right)$ were higher than 0.85 , indicating that the model proposed, i.e., the second-order quadratic model, fit well into the simulated data.

Table 2. Kinetic parameters of energy transfer.

\begin{tabular}{ccccc}
\hline \multirow{2}{*}{ Wavelength (nm) } & Minimum Energy Transfer $E_{\boldsymbol{o}}$ & \multicolumn{3}{c}{ Fitting Coefficients } \\
\cline { 3 - 5 } & (a.u.) & $\boldsymbol{\alpha}$ & $\boldsymbol{\beta}$ & $\boldsymbol{R}^{\mathbf{2}}$ \\
\hline $1064 \mathrm{~nm}$ & 163.22 & -0.06 & 7.91 & 0.89 \\
\hline
\end{tabular}

The $\mathrm{TiO}_{2}$ layer was introduced to the sensor structure between the Ag layer and the BK7 substrate, with the optimum thickness of $\mathrm{Ag}(60 \mathrm{~nm})$. Figure 4a shows the correspond- 
ing SPR characteristic curve based on the sensor structure of the $\mathrm{BK} 7 / \mathrm{TiO}_{2} / \mathrm{Ag} /$ sensing medium for different thicknesses of $\mathrm{TiO}_{2}$ from 80 to $160 \mathrm{~nm}$. It was observed that the SPR resonant angle did not change, and the contrast of the SPR curve was lightly changed (Figure $4 \mathrm{~b}$ ). The sensor properties were estimated and are shown in Table 3 . The results show that the sensitivity did not depend on the thickness of the $\mathrm{TiO}_{2}$ layer. However, the sensor detection accuracy was associated with the $\mathrm{TiO}_{2}$ thickness. When the thickness of $\mathrm{TiO}_{2}$ increases, the accuracy of the sensor detection is increased. The maximum detection accuracy of $15.87 /^{\circ}$, which was 1.14 times higher than that of the other cases using various thicknesses of $\mathrm{TiO}_{2}$, i.e., thicknesses of 80,100 , and $120 \mathrm{~nm}$, was obtained based on the $\mathrm{TiO}_{2}$ thickness of $140 \mathrm{~nm}$. The $\mathrm{TiO}_{2}$ layer not only enhances the sensor detection accuracy, but it also increases the adhesion between the Ag layer and prism [37].
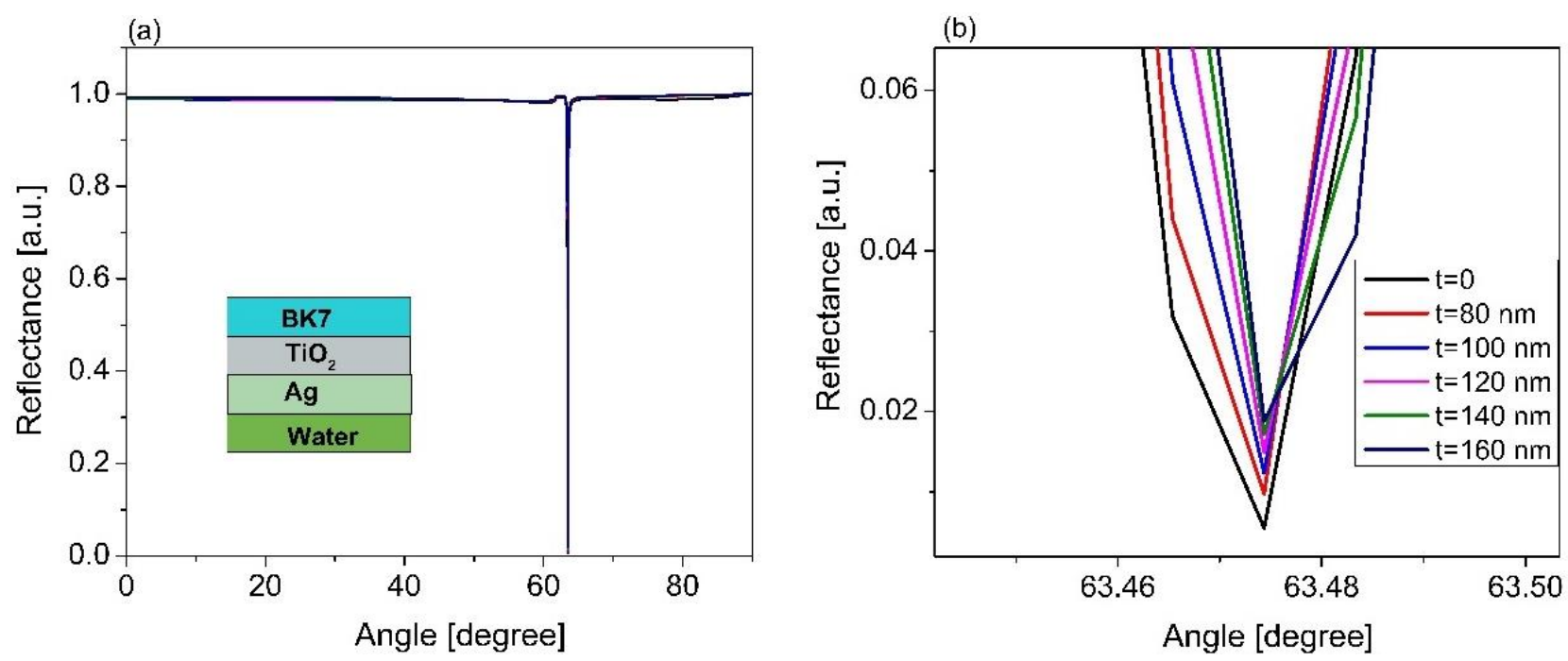

Figure 4. (a) Simulated results of $\mathrm{TiO}_{2}$ thickness changed from $80 \mathrm{~nm}$ to $160 \mathrm{~nm}$ based on the sensor structure of the $\mathrm{BK} 7 / \mathrm{TiO}_{2} / \mathrm{Ag} /$ sensing medium; (b) magnified view of (a).

Table 3. Estimation of the sensitivity and detection accuracy of the $\mathrm{BK} 7 / \mathrm{TiO}_{2} / \mathrm{Ag}$-based sensor.

\begin{tabular}{cccccc}
\hline $\mathbf{T i O}_{\mathbf{2}}$ & $\mathbf{8 0} \mathbf{~ n m}$ & $\mathbf{1 0 0} \mathbf{~ m}$ & $\mathbf{1 2 0} \mathbf{~ n m}$ & $\mathbf{1 4 0} \mathbf{~ n m}$ & $\mathbf{1 6 0} \mathbf{~ n m}$ \\
\hline Sensor sensitivity $\left({ }^{\circ} / \mathrm{RIU}\right)$ & 92.09 & 92.09 & 92.55 & 92.09 & 92.55 \\
\hline Detection accuracy $\left(/^{\circ}\right)$ & 13.88 & 13.89 & 13.89 & 15.87 & 15.87 \\
\hline
\end{tabular}

Based on the results obtained, the $\mathrm{Ag}$ thickness of $60 \mathrm{~nm}$ and the $\mathrm{TiO}_{2}$ of $140 \mathrm{~nm}$ were used to estimate the thickness of the AlAs layer. We scanned the AlAs thickness from 5 to $30 \mathrm{~nm}$ to maximize $\mathrm{FOM}$ for a given thickness of $\mathrm{Ag}$ and $\mathrm{TiO}_{2}$, as mentioned above. Figure 5 displays the reflectance for varying the AlAs thickness. When the AlAs thickness was increased, the SPR angle slightly shifted and the reflectance was slightly decreased. Based on those results, the sensor sensitivity and the FOM were estimated, as seen in Figure 6. The results show that an increase in the AlAs thickness was associated with an increment in the sensor sensitivity (Figure 6a). 
(a)
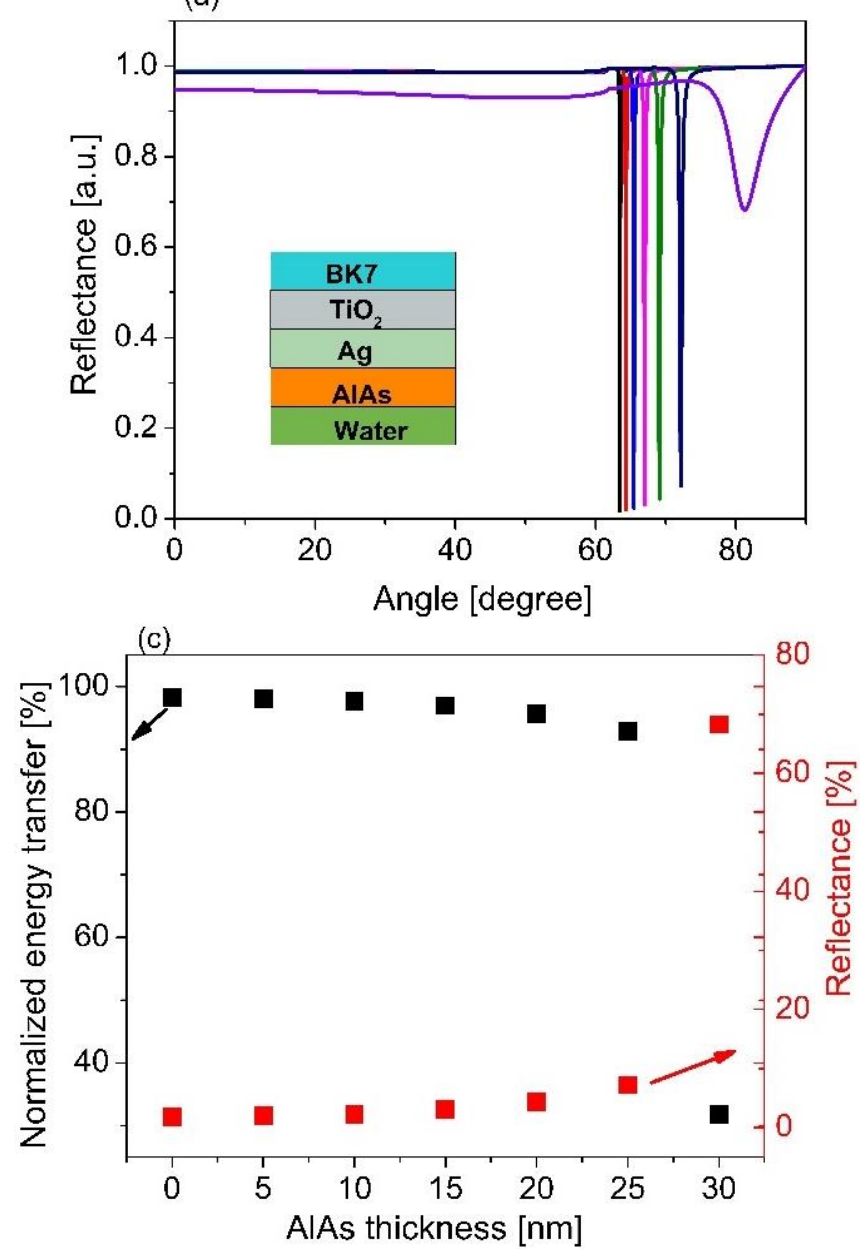

(b)
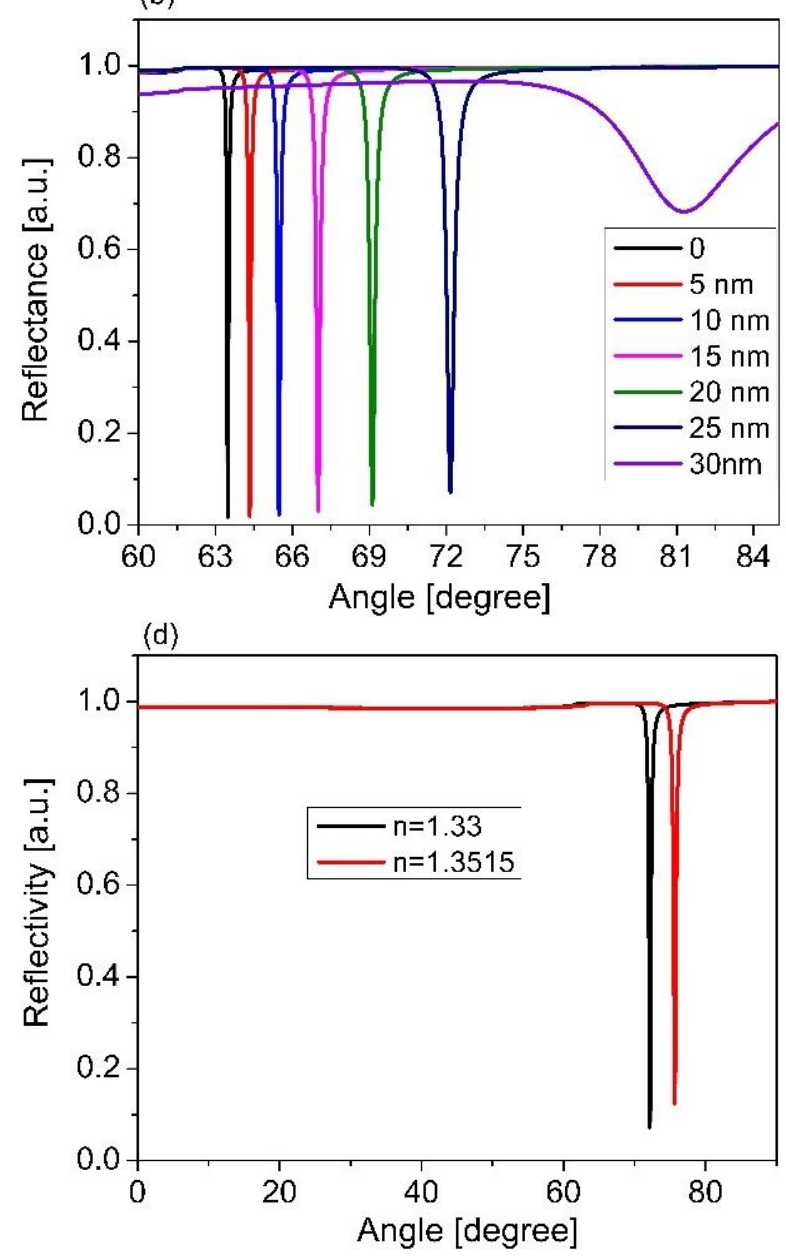

Figure 5. SPR spectra for varying thicknesses of $\mathrm{AlAs}$ based on the sensor structure of the $\mathrm{BK} 7 / \mathrm{TiO}_{2} / \mathrm{Ag} / \mathrm{AlAs} / \mathrm{sensing}$ medium; (b) magnified view of (a); (c) the relationship between energy transfer and the AlAs thickness; (d) the change in resonance for different $\mathrm{RI}$ of the sensing medium based on the sensor structure of $\mathrm{BK} 7 / \mathrm{TiO}_{2}(140 \mathrm{~nm}) / \mathrm{Ag}(60 \mathrm{~nm}) / \mathrm{AlAs}$ $(25 \mathrm{~nm})$.
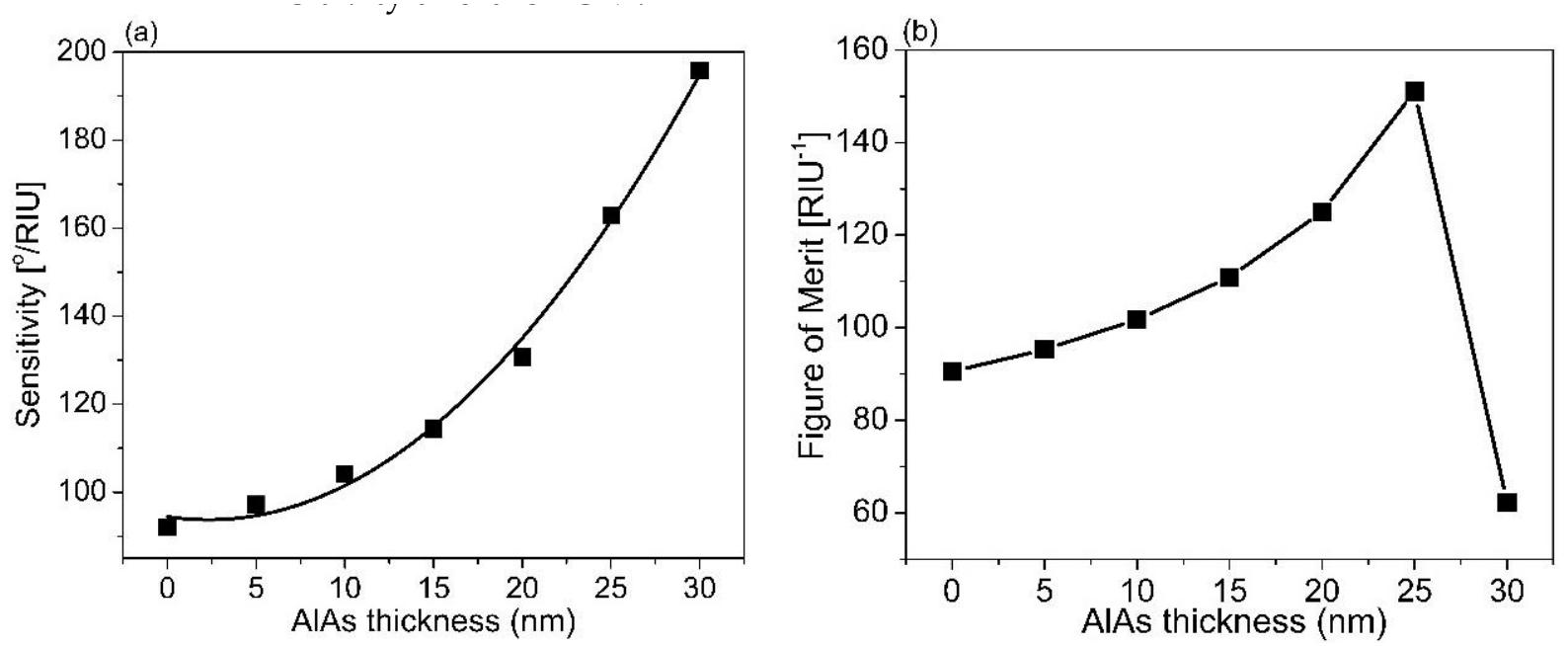

Figure 6. (a) The dependence of sensor sensitivity versus the thickness of the AlAs layer; (b) The comparison of the FOM of the sensor performance for various AlAs thicknesses. 
The parabolic shape with a quadratic second-order equation $S=S_{o}+a x+b x^{2}$ was fitted to the estimated results in Figure 6a to find the ideal characteristic parabolic relationship of the sensor sensitivity with the AlAs thickness during the sensor operating process. The fitting results show that the minimum possible sensitivity $\left(S_{o}\right)$ based on the multilayer structure was around $94.45^{\circ} / \mathrm{RIU}$ for the case of the AlAs layer, as illustrated in Table 4. The results also show that the optimum sensor sensitivity of $162.79^{\circ} / \mathrm{RIU}$ in the case of the AlAs layer (thickness of $25 \mathrm{~nm}$ ) increased $43.42 \%$ in comparison without utilizing the AlAs layer. In addition, this sensitivity was also better than that of the other cases using various thicknesses of AlAs layer, i.e., thicknesses of 5, 10, 15, and $20 \mathrm{~nm}$ with the sensitivity increments of $40.29 \%, 36.0 \%$, and $19.71 \%$, respectively. Moreover, the correlation coefficient $\left(R^{2}\right)$ was higher than 0.98 , indicating that the model proposed, i.e., the second-order quadratic model, fit well into the estimated data.

Table 4. Kinetic parameters for sensor sensitivity performance with three different materials of outermost layer (AlAs, $\mathrm{ZnO}$, and $\mathrm{MoO}_{3}$ ).

\begin{tabular}{ccccc}
\hline \multirow{2}{*}{ Sensor Sensitivity $S_{\boldsymbol{o}}\left({ }^{\circ} / \mathbf{R I U}\right)$} & \multicolumn{3}{c}{ Fitting Coefficients } \\
\cline { 3 - 5 } & & $\boldsymbol{a}$ & $\boldsymbol{b}$ & $\boldsymbol{R}^{\mathbf{2}}$ \\
\hline $\mathrm{AlAs}$ & 94.45 & -0.61 & 0.13 & 0.99 \\
\hline $\mathrm{ZnO}$ & 93.11 & -0.03 & 0.03 & 0.96 \\
\hline $\mathrm{MoO}_{3}$ & 93.55 & -0.14 & 0.04 & 0.96 \\
\hline
\end{tabular}

Based on this prediction model, the thicker the AlAs layer is, the more sensitive the sensing performance is. However, when an increment in the AlAs layer was over $25 \mathrm{~nm}$, this caused an increment in reflectance of around $70 \%$. The reflectivity was higher than $50 \%$, leading to the fact that there was a smaller coupling effect between the TM wave and the evanescent wave to generate SPR. This led us to obtain a lower value of FOM, as shown in Figure 6b. The maximum FOM was obtained around 150/RIU with the AlAs layer of $25 \mathrm{~nm}$ thickness. It is worth mentioning that this value of FOM obtained with an AlAs thickness of $25 \mathrm{~nm}$ was $41.06 \%$ and $60.26 \%$ higher than that of the case without using the AlAs layer and the AlAs layer of $30 \mathrm{~nm}$ thickness, respectively, as illustrated in Figure $6 \mathrm{~b}$. It is generally seen that the larger the FOM is, the better the sensitivity is. This result obtained is higher than that of other works using a plasmonic gold layer. Table 5 represents a comparison of the sensor proposed with the existing plasmonic sensors, which were found in the literature. In this case, we made a comparison of several aspects, i.e., the sensor structure, RI range, FOM, and operating wavelength. It can be generally seen that the sensor proposed shows better FOM than the existing sensors [54-65], which used expensive materials such as Au-coated fiber for SPR excitation. This form of a multilayer $\left(\mathrm{TiO}_{2}(140 \mathrm{~nm}) / \mathrm{Ag}(60 \mathrm{~nm}) / \mathrm{AlAs}(25 \mathrm{~nm})\right)$ can be suitable for the implementation of a SPR sensor based on BK7 glass subtrate for an improvement in the detection efficiency of a small amount of bio-chemical agents, due to the enhancement of the evanescent field's penetration depth into the sensing medium, leading to an enhancement of the sensor sensitivity and the FOM.

To check the relevance of the chosen material for SPR sensor performance, AlAs, we also performed control simulations with two more materials, $\mathrm{ZnO}$ and $\mathrm{MoO}_{3}$, which are usually used as the outermost layer in place of AlAs. Figure 7a represents the SPR spectra for a structure of $\mathrm{BK} / \mathrm{TiO}_{2} / \mathrm{Ag} / \mathrm{ZnO}$ with various thicknesses of $\mathrm{ZnO}$. Similar to Figure 5a, SPR dips were observed. It was further obtained that the SPR curve shifted, with an increase in the $\mathrm{ZnO}$ thickness. The SPR curve possessed a very low contrast and was quite broad in the case of the $\mathrm{ZnO}$ layer thickness of $30 \mathrm{~nm}$ (Figure $7 \mathrm{~b}$ ). The energy transfer and reflectivity are also presented as seen in Figure 7c. In addition, the SPR spectra for varying analyte refractive indices based on the optimized configuration of $\mathrm{BK} 7 / \mathrm{TiO}_{2} / \mathrm{Ag} / \mathrm{ZnO}$ are shown in Figure $7 \mathrm{~d}$. It was observed that the resonant angle increased with an increase in the refractive index of the sensing medium, while the contract 
of the SPR dip slightly decreased with an increase in the refractive index of the sensing medium. Figure $8 \mathrm{a}, \mathrm{b}$ present the estimated sensor sensitivity and the FOM for the sensor structure of $\mathrm{BK} 7 / \mathrm{TiO}_{2} / \mathrm{Ag} / \mathrm{ZnO}$, respectively. The results show that the maximum sensitivity and the $\mathrm{FOM}$ in the case of $\mathrm{BK} 7 / \mathrm{TiO}_{2} / \mathrm{Ag} / \mathrm{ZnO}$ were 1.5 times and 1.45 times lower than that of the case of $\mathrm{BK} / \mathrm{TiO}_{2} / \mathrm{Ag} / \mathrm{AlAs}$, respectively. In addition, Figure $9 \mathrm{a}$ illustrates the SPR spectra for different thicknesses of $\mathrm{MoO}_{3}$ film in $\mathrm{BK} 7 / \mathrm{TiO}_{2} / \mathrm{Ag} / \mathrm{MoO}_{3}$ configuration with the optimum thickness of $\mathrm{TiO}_{2}(140 \mathrm{~nm})$ and $\mathrm{Ag}$ film $(60 \mathrm{~nm})$. A similar phenomenon in the case of $\mathrm{ZnO}$ film was observed. The resonance angle and contrast, as well as the width of the SPR curves changed with an increase in the $\mathrm{MoO}_{3}$ thickness, as shown in Figure 9b,c. In addition, the SPR spectra for varying analyte refractive indices based on the optimized configuration of $\mathrm{BK} 7 / \mathrm{TiO}_{2} / \mathrm{Ag} / \mathrm{MoO}_{3}$ are shown in Figure $9 \mathrm{~d}$. It was observed that the resonant angle and the contract of the SPR dip increased with an increase in the refractive index of the sensing medium. Moreover, a change in the sensor sensitivity and the FOM were also estimated, which were found to be maximum for the $\mathrm{MoO}_{3}$ thickness of $25 \mathrm{~nm}$, as seen in Figure 10. It can also be observed that for the structure of $\mathrm{BK} 7 / \mathrm{TiO}_{2} / \mathrm{Ag} / \mathrm{AlAs}$ (as represented in Figure $5 \mathrm{~d}$ ), compared with both $\mathrm{BK} 7 / \mathrm{TiO}_{2} / \mathrm{Ag} / \mathrm{ZnO}$ and $\mathrm{BK} 7 / \mathrm{TiO}_{2} / \mathrm{Ag} / \mathrm{MoO}_{3}$, the shift in resonant angle was larger for the same refractive index change (Figures $7 \mathrm{~d}$ and $9 \mathrm{~d}$ ). That led us to obtain better sensitivity for the case of $\mathrm{BK} 7 / \mathrm{TiO}_{2} / \mathrm{Ag} / \mathrm{AlAs}$, as mentioned above.
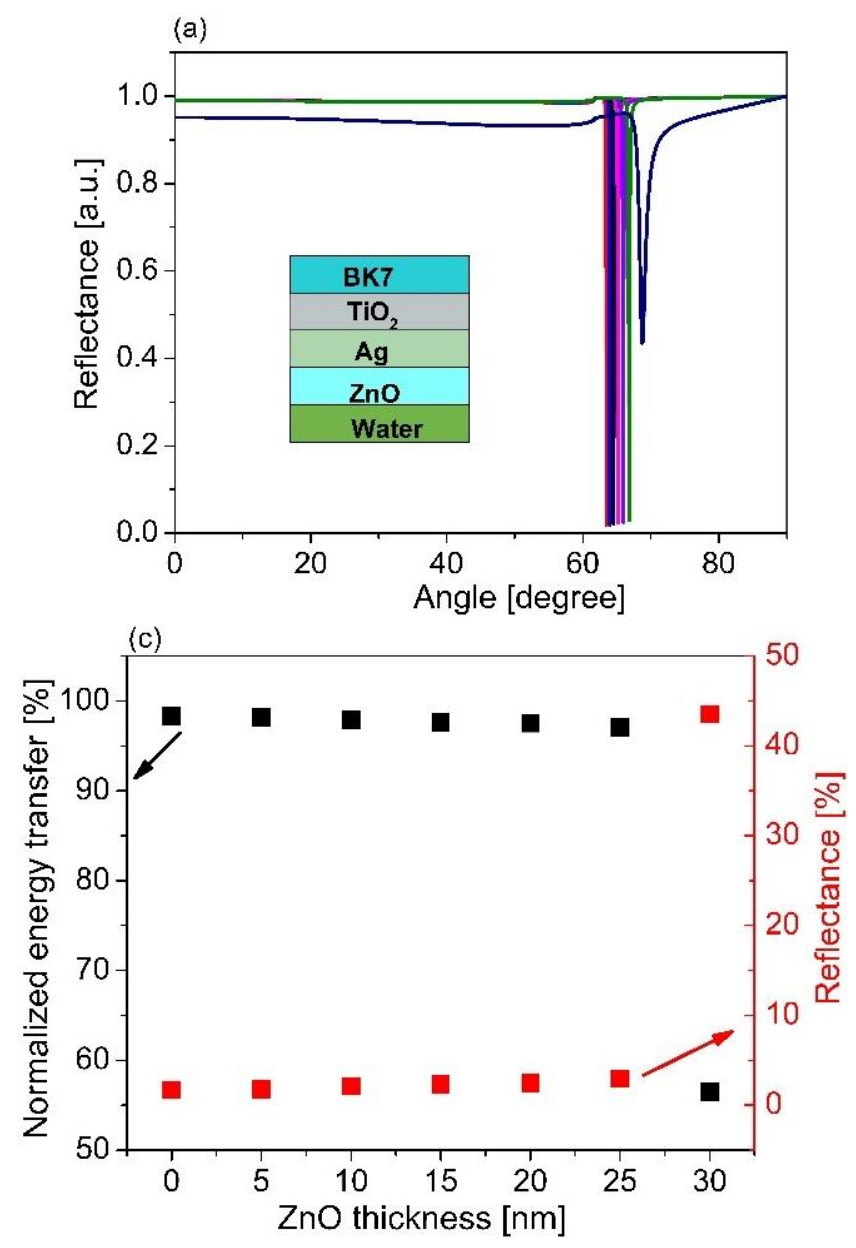

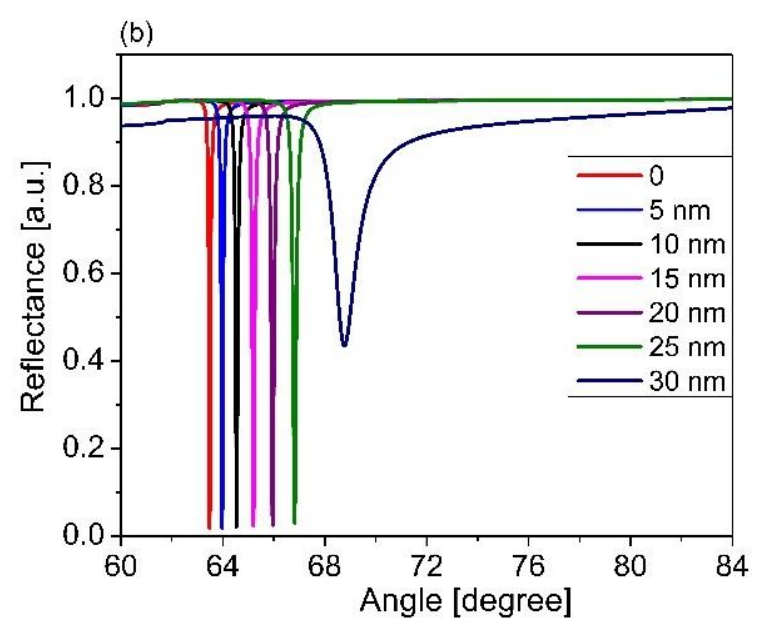

(d)

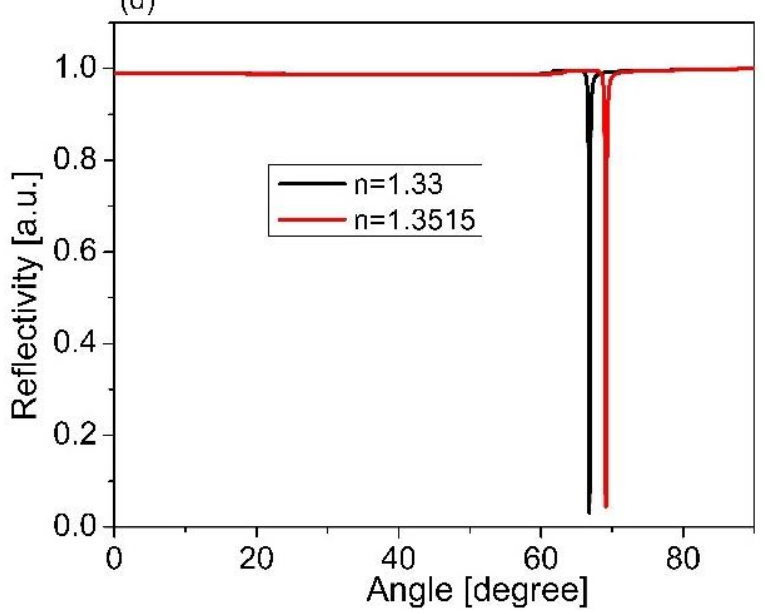

Figure 7. SPR spectra for varying thicknesses of $\mathrm{ZnO}$ based on the sensor structure of the $\mathrm{BK} 7 / \mathrm{TiO}_{2} / \mathrm{Ag} / \mathrm{ZnO} / \mathrm{sensing}$ medium; (b) magnified view of (a); (c) the relationship between energy transfer and the ZnO thickness; (d) the change in resonance for different $\mathrm{RI}$ of the sensing medium based on the sensor structure of $\mathrm{BK} 7 / \mathrm{TiO}_{2}(140 \mathrm{~nm}) / \mathrm{Ag}(60 \mathrm{~nm}) / \mathrm{ZnO}$ $(25 \mathrm{~nm})$. 

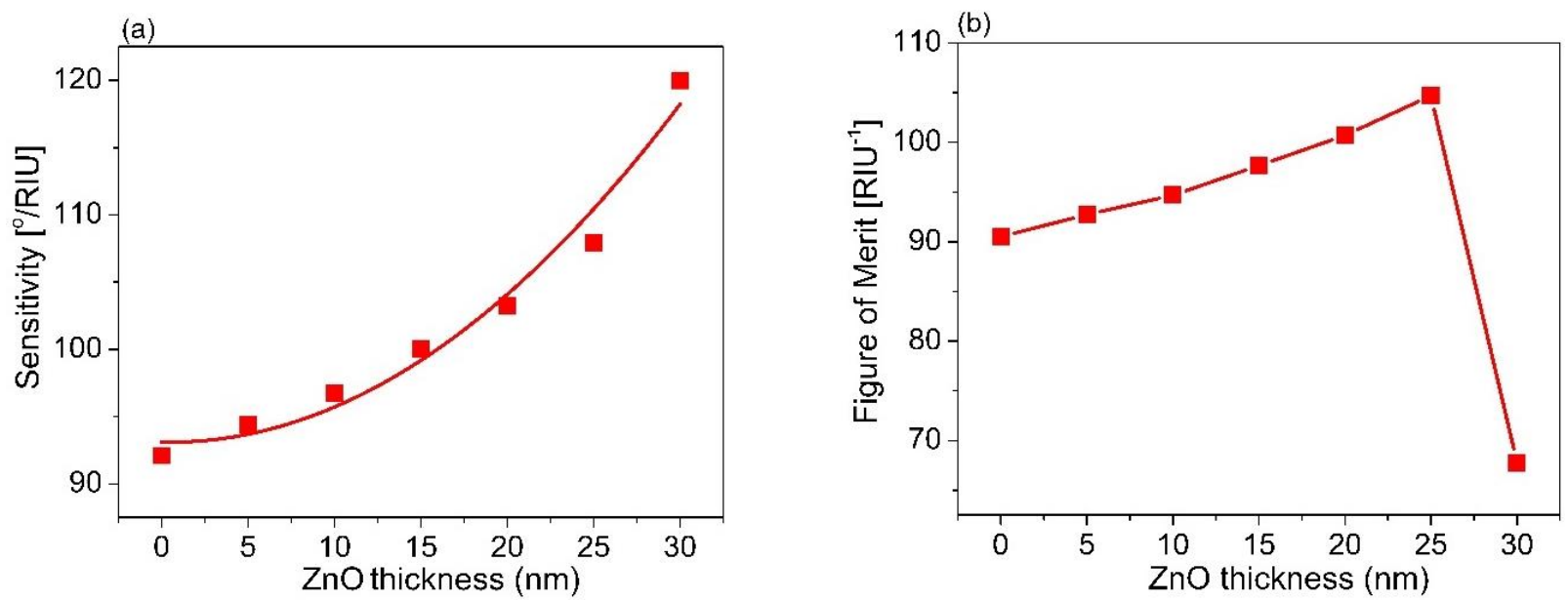

Figure 8. (a) The dependence of sensor sensitivity versus the thickness of the ZnO layer; (b) The comparison of the FOM of the sensor performance for various $\mathrm{ZnO}$ thicknesses.

(a)
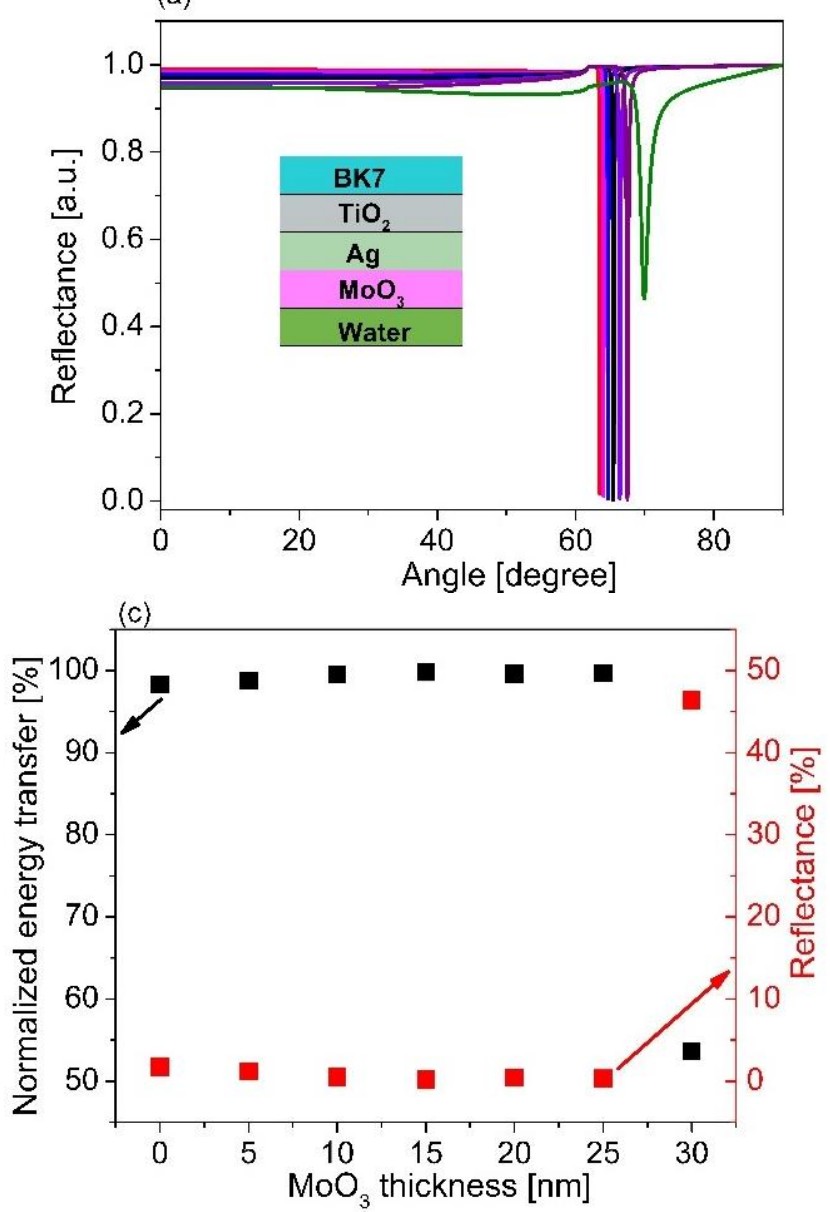

(b)

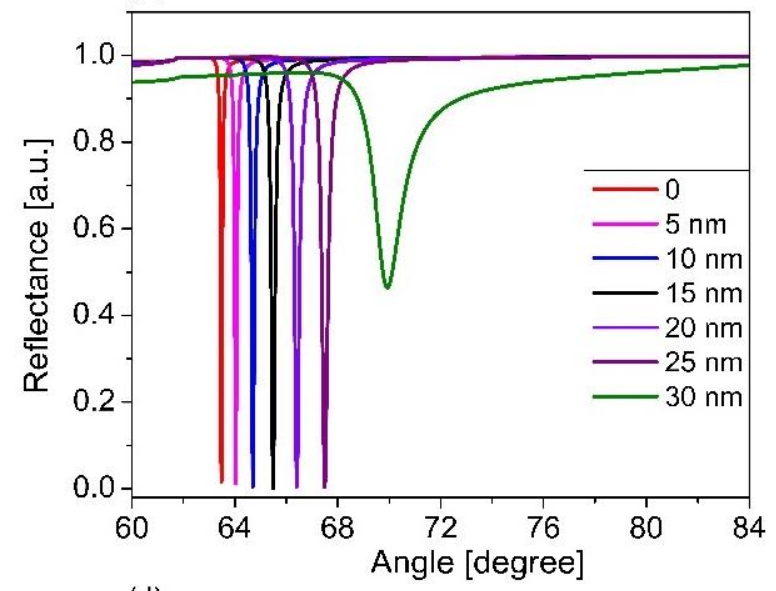

(d)

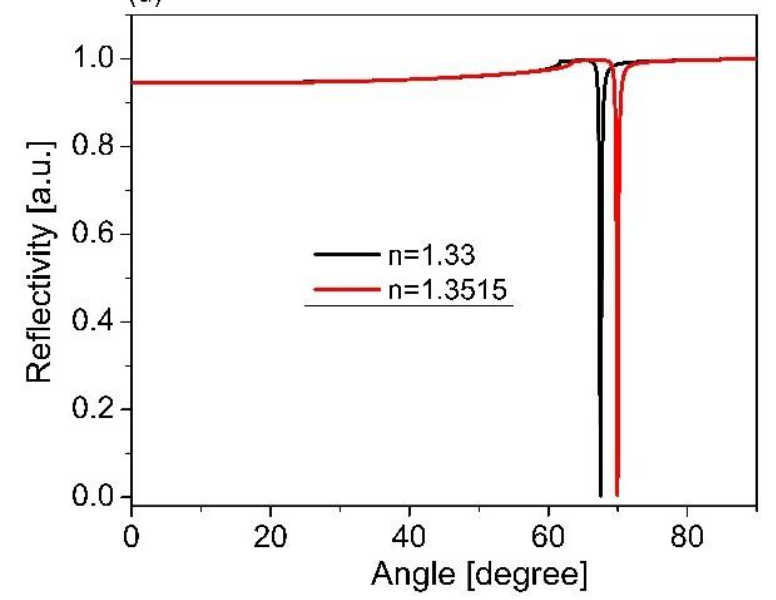

Figure 9. SPR spectra for varying thicknesses of $\mathrm{MoO}_{3}$ based on the sensor structure of the $\mathrm{BK} 7 / \mathrm{TiO}_{2} / \mathrm{Ag} / \mathrm{MoO} 3 /$ sensing medium; (b) magnified view of (a); (c) the relationship between energy transfer and the $\mathrm{MoO}_{3}$ thickness; (d) the change in resonance for different RI of the sensing medium based on the sensor structure of $\mathrm{BK} / \mathrm{TiO}_{2}(140 \mathrm{~nm}) / \mathrm{Ag}(60 \mathrm{~nm}) / \mathrm{MoO} 3$ $(25 \mathrm{~nm})$. 

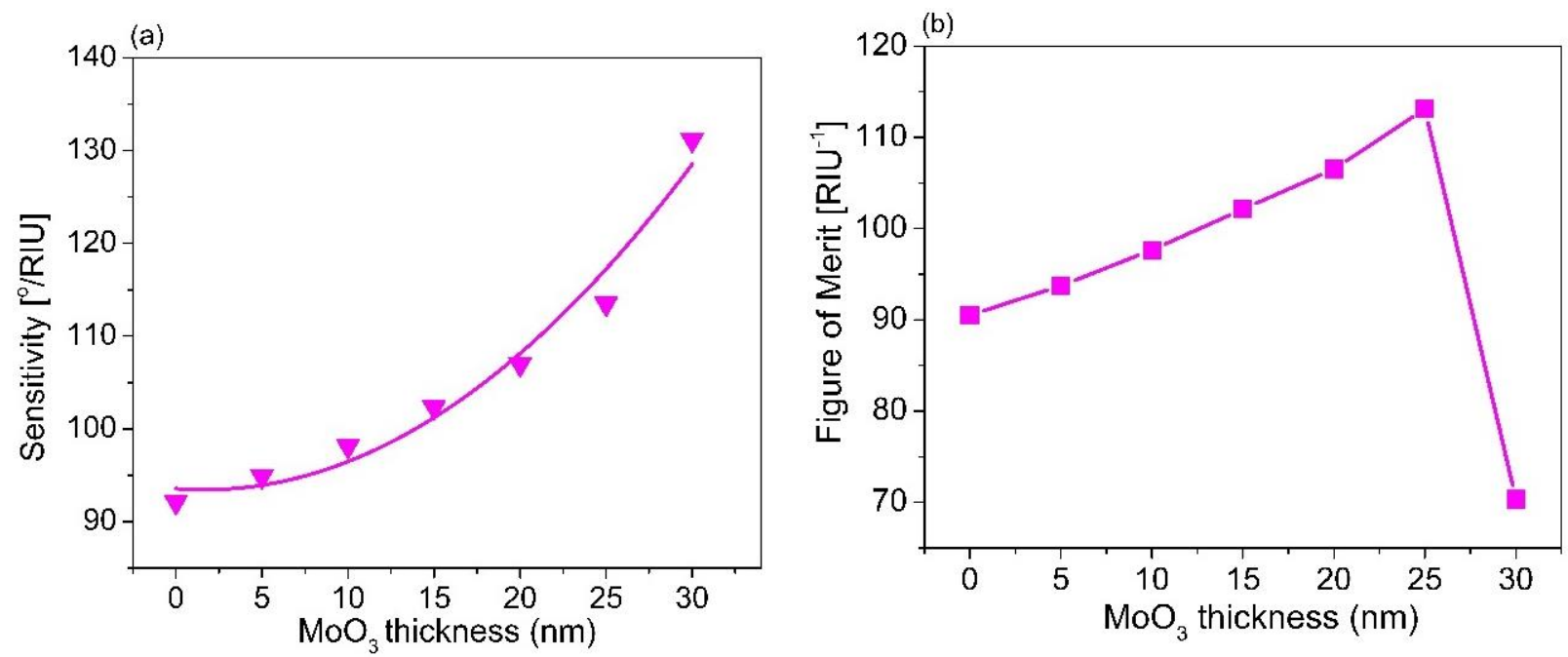

Figure 10. (a) The dependence of sensor sensitivity versus the thickness of the $\mathrm{MoO}_{3}$ layer; (b) The comparison of the FOM of the sensor performance for various $\mathrm{MoO}_{3}$ thicknesses.

To demonstrate our point, we plotted the field profiles for three different sensor structures including $\mathrm{BK} 7 / \mathrm{TiO}_{2}(140 \mathrm{~nm}) / \mathrm{Ag}(60 \mathrm{~nm}) / \mathrm{AlAs}(25 \mathrm{~nm}) ; \mathrm{prism} / \mathrm{TiO}_{2}(140 \mathrm{~nm}) / \mathrm{Ag}$ $(60 \mathrm{~nm}) / \mathrm{ZnO}(25 \mathrm{~nm})$; and prism $/ \mathrm{TiO}_{2}(140 \mathrm{~nm}) / \mathrm{Ag}(60 \mathrm{~nm}) / \mathrm{MoO}_{3}(25 \mathrm{~nm})$, as shown in Figure 11. The simulated results show that the field in the analyte for the sensor structure of $\mathrm{BK} 7 / \mathrm{TiO}_{2}(140 \mathrm{~nm}) / \mathrm{Ag}(60 \mathrm{~nm}) / \mathrm{AlAs}(25 \mathrm{~nm})$ was stronger than that of the other ones. This was in agreement with the results of the sensitivity analysis and FOM, as discussed above. This phenomenon could be caused by the contribution of the imaginary part of the dielectric constant of the Ag layer, combined with the large real part of the dielectric constant of the AlAs layer, as shown in Table 1. The larger the dielectric constant is, the stronger the field and the deeper the penetration. That also led us to believe that the sensor based on $\mathrm{BK} / \mathrm{TiO}_{2}(140 \mathrm{~nm}) / \mathrm{Ag}(60 \mathrm{~nm}) / \mathrm{AlAs}(25 \mathrm{~nm})$ can be utilized for the detection of analytes with a larger size, such as bacteria, proteins, and cells.

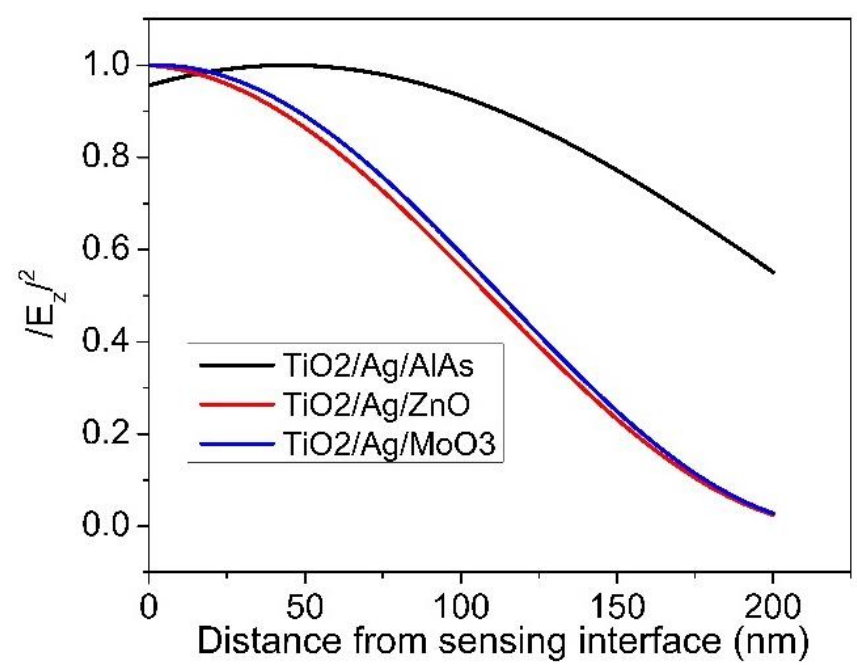

Figure 11. Field profiles for the proposed sensor structures of $\mathrm{BK} / \mathrm{TiO}_{2}(140 \mathrm{~nm}) / \mathrm{Ag}(60 \mathrm{~nm}) / \mathrm{AlAs}$ $(25 \mathrm{~nm}) ; \operatorname{prism} / \mathrm{TiO}_{2}(140 \mathrm{~nm}) / \mathrm{Ag}(60 \mathrm{~nm}) / \mathrm{ZnO}(25 \mathrm{~nm}) ;$ and $\mathrm{prism} / \mathrm{TiO}_{2}(140 \mathrm{~nm}) / \mathrm{Ag}$ $(60 \mathrm{~nm}) / \mathrm{MoO}_{3}(25 \mathrm{~nm})$.

The combination of $\mathrm{Ag}$ with the other materials such as $\mathrm{TiO}_{2}$ and $\mathrm{AlAs}$ for implementation of the SPR sensor with the operating wavelength of $1064 \mathrm{~nm}$ offers several benefits. The FOM of the SPR sensor based on the combination of $\mathrm{TiO}_{2} / \mathrm{Ag} / \mathrm{AlAs}$ is better 
than that of the sensor using expensive materials such as $\mathrm{Au}$. In addition, the use of $\mathrm{TiO}_{2}$ between the prism and the Ag layer provides higher detection accuracy, allowing possible reproducibility of the sensor performance for the detection of bio-targets. Moreover, the simulated results present the possibility of the use of the combination materials with the IR laser for SPR excitation, offering a new research area for bio-sensing applications.

Table 5. Performance of SPR-based sensors.

\begin{tabular}{|c|c|c|c|c|}
\hline Optical Structure & RI Range & Wavelength & FOM & Reference \\
\hline $\mathrm{TiO}_{2} / \mathrm{Ag} / \mathrm{AlAs}$-coated prism & $1.33-1.3515$ & $1064 \mathrm{~nm}$ & $\sim 150 \mathrm{RIU}^{-1}$ & This work \\
\hline $\mathrm{ZnO}$-coated U-shaped fiber & $1.34-1.42$ & $350-600 \mathrm{~nm}$ & $\sim 2.4 \mathrm{RIU}^{-1}$ & [54] \\
\hline Au-coated fiber & $1.3345-1.3592$ & $300-800 \mathrm{~nm}$ & $\sim 21.2 \mathrm{RIU}^{-1}$ & [55] \\
\hline Au-coated tapered coreless fiber & 1.33-1.391 & $350-1000 \mathrm{~nm}$ & $\sim 12.6 \mathrm{RIU}^{-1}$ & [56] \\
\hline $\begin{array}{l}\text { Au-coated hetero-core structure } \\
\text { fiber }\end{array}$ & $1.333-1385$ & $300-1700 \mathrm{~nm}$ & $\sim 33.8 \mathrm{RIU}^{-1}$ & [57] \\
\hline S-tapered fiber & $1.332-1.387$ & $1200-1600 \mathrm{~nm}$ & $\sim 125.5 \mathrm{RIU}^{-1}$ & [58] \\
\hline Au-coated fiber & $1.30-1.34$ & $300-1700 \mathrm{~nm}$ & $\sim 61.2 \mathrm{RIU}^{-1}$ & [59] \\
\hline Au-coated few-mode fiber & $1.333-1.404$ & $300-1100 \mathrm{~nm}$ & $\sim 42.2 \mathrm{RIU}^{-1}$ & [60] \\
\hline $\begin{array}{c}\text { Au-coated hetero-core structure } \\
\text { fiber }\end{array}$ & $1.333-1.3836$ & $400-800 \mathrm{~nm}$ & $\sim 530 \mathrm{RIU}^{-1}$ & [61] \\
\hline Au-coated fiber & $1.335-1.385$ & $360-1700 \mathrm{~nm}$ & 13.9 $\mathrm{RIU}^{-1}$ & [62] \\
\hline S-tapered fiber & $1.336-1.340$ & $1520-1580 \mathrm{~nm}$ & 96.1 $\mathrm{RIU}^{-1}$ & [63] \\
\hline $\mathrm{Ag} / \mathrm{Au} / \mathrm{MoS}_{2}$-coated optical fiber & $1.33-1.37$ & $300-700 \mathrm{~nm}$ & $\sim 23.29 \mathrm{RIU}^{-1}$ & [64] \\
\hline Au-coated plastic optical fiber & $1.34-1.42$ & $360-2500 \mathrm{~nm}$ & $\sim 25.4 \mathrm{RIU}^{-1}$ & [65] \\
\hline
\end{tabular}

\section{Conclusions}

This work presented the numeric investigation of the SPR sensor with a structure comprising prism $/ \mathrm{TiO}_{2} / \mathrm{Ag} / \mathrm{AlAs}$ and an operating wavelength of $1064 \mathrm{~nm}$. The resonant spectra can be efficiently realized by adjusting the thicknesses of the $\mathrm{TiO}_{2}, \mathrm{Ag}$, and $\mathrm{AlAs}$ layers. The FOM of the proposed sensor was achieved around 150/RIU, corresponding to the sensor sensitivity of $162.79^{\circ} / \mathrm{RIU}$ with the optimized thicknesses of the $\mathrm{TiO}_{2}, \mathrm{Ag}$, and AlAs layers of 140, 60, and $25 \mathrm{~nm}$, respectively. The sensors' responses were compared with two SPR sensor configurations using $\mathrm{ZnO}$ and $\mathrm{MoO}_{3}$ in place of AlAs. It is anticipated that the proposed SPR sensor structure can be utilized for various applications such as the quantitative detection of bio-molecules with enhanced figure of merits.

Author Contributions: N.V.S. proposed the algorithm for the SPR sensor models and performed numerical computations and simulations; Q.M.N. and G.E. corrected the SPR sensor models and edited the manuscript; N.Q.T. and N.T.P.A. performed formal analysis and wrote part of the text; T.T.N. supervised the whole process, writing the initial draft and editing the final manuscript. All authors have read and agreed to the published version of the manuscript.

Funding: This research was supported by Tra Vinh University under grant contract number 155/2021/ HĐ.HĐKH-ĐHTV and also funded by Vietnam National Foundation for Science and Technology Development (NAFOSTED) under grant number 103.03-2018.351.

Acknowledgments: The authors acknowledge the technical support from the editors.

Conflicts of Interest: The authors report no conflicts of interest in this work.

\section{References}

1. Quinn, J.G.; O’Neill, S.; Doyle, A.; McAtamney, C.; Diamond, D.; MacCraith, B.D.; O'Kennedy, R. Development and application of surface plasmon resonance-based biosensors for the detection of cell-ligand interactions. Anal. Biochem. 2000, 281, 135-143. [CrossRef]

2. Chiu, M.H.; Shih, C.H.; Chi, M.H. Optimum sensitivity of single-mode D-type optical fiber sensor in the intensity measurement. Sens. Actuators B Chem. 2007, 123, 1120-1124. [CrossRef]

3. Jang, H.S.; Park, K.N.; Kang, C.D.; Kim, J.P.; Sim, S.J.; Lee, K.S. Optical fiber SPR biosensor with sandwich assay for the detection of prostate specific antigen. Opt. Commun. 2009, 282, 2827-2830. [CrossRef]

4. Yanase, Y.; Araki, A.; Suzuki, H.; Tsutsui, T.; Kimura, T.; Okamoto, K.; Hide, M. Development of an optical fiber SPR sensor for living cell activation. Biosens. Bioelectron. 2010, 25, 1244-1247. [CrossRef] 
5. Kretschmann, E.; Raether, H. Notizen: Radiative decay of non-radiative surface plasmons excited by light. Z. Nat. A 1968, 23, 2135-2136. [CrossRef]

6. Wu, S.Y.; Ho, H.P.; Law, W.C.; Lin, C.; Kong, S.K. Highly sensitive differential phase-sensitive surface plasmon resonance biosensor based on the Mach-Zehnder configuration. Opt. Lett. 2004, 29, 2378-2380. [CrossRef]

7. Telezhnikova, O.; Homola, J. New approach to spectroscopy of surface plasmons. Opt. Lett. 2006, 31, 3339-3341. [CrossRef]

8. Yuan, W.; Ho, H.P.; Wong, C.L.; Kong, S.K.; Lin, C. Surface plasmon resonance biosensor incorporated in a Michelson interferometer with enhanced sensitivity. IEEE Sens. J. 2007, 7, 70-73. [CrossRef]

9. Yang, X.; Yuan, Y.; Dai, Z.; Liu, F.; Huang, J. Optical property and adsorption isotherm models of glucose sensitive membrane based on prism SPR sensor. Sens. Actuators B Chem. 2016, 237, 150-158. [CrossRef]

10. Mitsushio, M.; Miyashita, K.; Higo, M. Sensor properties and surface characterization of the metal-deposited SPR optical fiber sensors with Au, Ag, Cu, and Al. Sens. Actuators A Phys. 2006, 125, 296-303. [CrossRef]

11. Vema, R.K.; Sharma, A.K.; Gupta, B.D. Surface plasmon resonance based tapered fiber optic sensor with different taper profiles. Opt. Commun. 2008, 281, 1486-1491.

12. Nguyen, T.T.; Lee, E.C.; Ju, H. Bimetal coated optical fiber sensors based on surface plasmon resonance induced change in birefringence and intensity. Opt. Express 2014, 22, 5590-5598. [CrossRef] [PubMed]

13. Nguyen, T.T.; Bea, S.O.; Kim, D.M.; Yoon, W.J.; Park, J.W.; An, S.S.A.; Ju, H. A regenerative label-free fiber optic sensor using surface plasmon resonance for clinical diagnosis of fibrinogen. Int. J. Nanomed. 2015, 10, 155.

14. Zhao, Y.; Lei, M.; Liu, S.X.; Zhao, Q. Smart hydrogel-based optical fiber SPR sensor for pH measurements. Sens. Actuators B Chem. 2018, 261, 226-232. [CrossRef]

15. Zhou, X.; Li, X.; Cheng, T.; Li, S.; An, G. Graphene enhanced optical fiber SPR sensor for liquid concentration measurement. Opt. Fiber Technol. 2018, 43, 62-66. [CrossRef]

16. Chung, Y.K.; Reboud, J.; Lee, K.C.; Lim, H.M.; Lim, P.Y.; Wang, K.Y.; Chen, Y. An electrical biosensor for the detection of circulating tumor cells. Biosens. Bioelectron. 2011, 26, 2520-2526. [CrossRef]

17. Kim, J.; Kim, S.; Nguyen, T.T.; Lee, R.; Li, T.; Yun, C.; Ju, H. Label-free quantitative immunoassay of fibrinogen in alzheimer disease patient plasma using fiber optical surface plasmon resonance. J. Electron. Mater. 2016, 45, 2354-2360. [CrossRef]

18. Nu, T.T.V.; Tran, N.H.T.; Nam, E.; Nguyen, T.T.; Yoon, W.J.; Cho, S.; Ju, H. Blood-based immunoassay of tau proteins for early diagnosis of Alzheimer's disease using surface plasmon resonance fiber sensors. RSC Adv. 2018, 8, 7855-7862. [CrossRef]

19. Souto, D.E.; Volpe, J.; Gonçalves, C.D.C.; Ramos, C.H.; Kubota, L.T. A brief review on the strategy of developing SPR-based biosensors for application to the diagnosis of neglected tropical diseases. Talanta 2019, 205, 120122. [CrossRef]

20. Srivastava, S.K.; Abdulhalim, I. Spectral interrogation based SPR sensor for blood glucose detection with improved sensitivity and stability. J. Biosens. Bioelectron. 2015, 6, 10-12.

21. Mudgal, N.; Saharia, A.; Agarwal, A.; Ali, J.; Yupapin, P.; Singh, G. Modeling of highly sensitive surface plasmon resonance (SPR) sensor for urine glucose detection. Opt. Quantum Electron. 2020, 52, 1-14. [CrossRef]

22. Croci, L.; Delibato, E.; Volpe, G.; De Medici, D.; Palleschi, G. Comparison of PCR, electrochemical enzyme-linked immunosorbent assays, and the standard culture method for detecting Salmonella in meat products. Appl. Environ. Microbiol. 2004, 70, 1393-1396. [CrossRef] [PubMed]

23. Taylor, A.D.; Ladd, J.; Yu, Q.; Chen, S.; Homola, J.; Jiang, S. Quantitative and simultaneous detection of four foodborne bacterial pathogens with a multi-channel SPR sensor. Biosens. Bioelectron. 2006, 22, 752-758. [CrossRef] [PubMed]

24. Vaisocherová-Lísalová, H.; Víšová, I.; Ermini, M.L.; Špringer, T.; Song, X.C.; Mrázek, J.; Homola, J. Low-fouling surface plasmon resonance biosensor for multi-step detection of foodborne bacterial pathogens in complex food samples. Biosens. Bioelectron. 2016, 80, 84-90. [CrossRef] [PubMed]

25. Kabashin, A.V.; Evans, P.; Pastkovsky, S.; Hendren, W.; Wurtz, G.A.; Atkinson, R.; Pollard, V.A.; Podolskiy, R.; Zayats, A.V. Plasmonic nanorod metamaterials for biosensing. Nat. Mater. 2009, 8, 867-871. [CrossRef]

26. Sreekanth, K.V.; Alapan, Y.; ElKabbash, M.; Ilker, E.; Hinczewski, M.; Gurkan, U.A.; Luca, A.D.; Strangi, G. Extreme sensitivity biosensing platform based on hyperbolic metamaterials. Nat. Mater. 2016, 15, 621-627. [CrossRef]

27. Garoli, D.; Calandrini, E.; Giovannini, G.; Hubarevich, A.; Caligiuri, V.; De Angelis, F. Nanoporous gold metamaterials for high sensitivity plasmonic sensing. Nanoscale Horiz. 2019, 4, 1153-1157. [CrossRef]

28. Nguyen, T.T.; Trinh, K.T.L.; Yoon, W.J.; Lee, N.Y.; Ju, H. Integration of a microfluidic polymerase chain reaction device and surface plasmon resonance fiber sensor into an inline all-in-one platform for pathogenic bacteria detection. Sens. Actuators B Chem. 2017, 242, 1-8. [CrossRef]

29. Jha, R.; Sharma, A.K. High-performance sensor based on surface plasmon resonance with chalcogenide prism and aluminum for detection in infrared. Opt. Lett. 2009, 34, 749-751. [CrossRef]

30. Pandey, A.K.; Sharma, A.K. Simulation and analysis of plasmonic sensor in NIR with fluoride glass and graphene layer. Photonics Nanostruct. Fundam. Appl. 2018, 28, 94-99. [CrossRef]

31. Van Sau, N.; Ngo, Q.M.; Phan, T.B.; Tran, N.Q.; Nguyen, T.T. Optical Biosensor Using Near Infrared Laser for Enhancement of Detection Accuracy. J. Electron. Mater. 2020, 49, 7420-7426. [CrossRef]

32. Liu, C.; Wang, J.; Jin, X.; Wang, F.; Yang, L.; Lv, J.; Fu, G.; Li, X.; Liu, Q.; Sun, T.; et al. Near-infrared surface plasmon resonance sensor based on photonics crystal fiber with big open rings. Optik 2020, 207, 164466. [CrossRef] 
33. Iga, M.; Seki, A.; Watanabe, K. Hetero-core structured fiber optic surface plasmon resonance sensor with silver film. Sens. Actuators B Chem. 2004, 101, 368-372. [CrossRef]

34. Sharma, A.K.; Gupta, B.D. Fiber optic sensor based on surface plasmon resonance with nanoparticle films. Photonics Nanostruct. Fundam. Appl. 2005, 3, 30-37. [CrossRef]

35. Zynio, S.A.; Samoylov, A.V.; Surovtseval, E.R.; Mirsky, V.M.; Shirshov, Y.M. Bimetallic layers increase sensitivity of affinity sensors based on surface plasmon resonance. Sensors 2002, 2, 62-70. [CrossRef]

36. Csete, M.; Kohazi-Kis, A.; Vass, C.S.; Sipos, A.; Szekeres, G.; Deli, M.; Osvay, K.; Bor, Z.S. Atomic force microscopical and surface plasmon resonance spectroscopical investigation of sub-micrometer metal gratings generated by UV laser based two beam interference in Au-Ag bimetallic layers. Appl. Surf. Sci. 2007, 253, 7662-7671. [CrossRef]

37. Gao, D.; Guan, C.; Wen, Y.; Zhong, X.; Yuan, L. Multi-hole fiber based surface plasmon resonance sensor operated at near-infrared wavelengths. Opt. Commun. 2014, 313, 94-98. [CrossRef]

38. Shafieyan, A.R.; Ranjbar, M.; Kameli, P. Localized surface plasmon resonance H2 detection by MoO3 colloidal nanoparticles fabricated by the flame synthesis method. Int. J. Hydrog. Energy 2019, 44, 18628-18638. [CrossRef]

39. Tabassum, R.; Gupta, B.D. Simultaneous tuning of electric field intensity and structural properties of ZnO: Graphene nanostructures for FOSPR based nicotine sensor. Biosens. Bioelectron. 2017, 91, 762-769. [CrossRef] [PubMed]

40. Passian, A.; Imam, N. Nanosystems, edge computing, and the next generation computing systems. Sensors 2019, 19, 4048. [CrossRef]

41. Saad, Y.; Selmi, M.; Gazzah, M.H.; Belmabrouk, H. Theoritical evaluation of a fiber-optic SPR biosensor based on a gold layer treated with thiol acid. EPJ Appl. Phys. 2018, 82, 31210. [CrossRef]

42. Ding, L.; Li, Y.Q.; Liu, X.Y.; Shen, J.H.; Zhang, S.H.; Guo, F.M. Weak light characteristics of potential biosensor unit. Micro Nano Lett. 2013, 8, 594-597. [CrossRef]

43. Nazemi, E.; Aithal, S.; Hassen, W.M.; Frost, E.H.; Dubowski, J.J. GaAs/AlGaAs heterostructure based photonic biosensor for rapid detection of Escherichia coli in phosphate buffered saline solution. Sens. Actuators B Chem. 2015, 207, 556-562. [CrossRef]

44. Tang, L.; Chun, I.S.; Wang, Z.; Li, J.; Li, X.; Lu, Y. DNA detection using plasmonic enhanced near-infrared photoluminescence of gallium arsenide. Anal. Chem. 2013, 85, 9522-9527. [CrossRef]

45. El-Gohary, S.H.; Choi, M.; Kim, Y.L.; Byun, K.M. Dispersion curve engineering of TiO2/silver hybrid substrates for enhanced surface plasmon resonance detection. Sensors 2016, 16, 1442. [CrossRef] [PubMed]

46. Jin, Z.; Guan, W.; Liu, C.; Xue, T.; Wang, Q.; Zheng, W.; Cui, X. A stable and high resolution optical waveguide biosensor based on dense TiO2/Ag multilayer film. Appl. Surf. Sci. 2016, 377, 207-212. [CrossRef]

47. Werner, W.S.M.; Glantschnig, K.; Ambrosch-Draxl, C. Optical constants and inelastic electron-scattering data for 17 elemental metals. J. Phys. Chem. Ref. Data 2009, 38, 1013-1092. [CrossRef]

48. Rakić, A.D.; Majewski, M.L. Modeling the optical dielectric function of GaAs and AlAs: Extension of Adachi's model. J. Appl. Phys. 1996, 80, 5909-5914. [CrossRef]

49. DeVore, J.R. Refractive indices of rutile and sphalerite. J. Opt. Soc. Am. 1951, 41, 416-419. [CrossRef]

50. Aguilar, O.; de Castro, S.; Godoy, M.P.; Dias, M.R.S. Optoelectronic characterization of $\mathrm{Zn}_{1-\mathrm{x}} \mathrm{Cd}_{\mathrm{x}} \mathrm{O}$ thin films as an alternative to photonic crystals in organic solar cells. Opt. Mater. Express 2019, 9, 3638-3648. [CrossRef]

51. Lajaunie, L.; Boucher, F.; Dessapt, R.; Moreau, P. Strong anisotropic influence of local-field effects on the dielectric response of $\alpha-\mathrm{MoO}_{3}$. Phys. Rev. B 2013, 88, 115141. [CrossRef]

52. Johnston, K.S.; Karlsen, S.R.; Jung, C.C.; Yee, S.S. New analytical technique for characterization of thin films using surface plasmon resonance. Mater. Chem. Phys. 1995, 42, 242-246. [CrossRef]

53. Gupta, B.D.; Sharma Anuj, K. Sensitivity evaluation of a multi-layered surface plasmon resonance based fiber optic sensor: A theoretical study. Sens. Actuators B Chem. 2005, 107, 40-46. [CrossRef]

54. Paliwal, N.; Punjabi, N.; John, J.; Mukherji, S. Design and fabrication of lossy mode resonance based U-shaped fiber optic refractometer utilizing dual sensing phenomenon. J. Lightw. Technol. 2016, 34, 4187-4194. [CrossRef]

55. Wang, W.; Mai, Z.; Chen, Y.; Wang, J.; Li, L.; Su, Q.; Li, X.; Hong, X. A label-free fiber optic SPR biosensor for specific detection of C-reactive protein. Sci. Rep. 2017, 7, 1-8. [CrossRef]

56. Ding, Z.W.; Lang, T.T.; Wang, Y.; Zhao, C.L. Surface plasmon resonance refractive index sensor based on tapered coreless optical fiber structure. J. Lightw. Technol. 2017, 35, 4734-4739. [CrossRef]

57. Liu, Z.; Liu, L.; Zhu, Z.; Zhang, Y.; Wei, Y.; Zhang, Y.; Yang, J.; Yuan, L. Dual-channel surface plasmon resonance refractive index sensor based on modified hetero-core structure fiber. Opt. Commun. 2017, 403, 290-295. [CrossRef]

58. Chen, C.; Yang, R.; Zhang, X.Y.; Wei, W.H.; Guo, Q.; Zhang, X.; Qin, L.; Ning, Y.Q.; Yu, Y.S. Compact refractive index sensor based on an S-tapered fiber probe. Opt. Mater. Express 2018, 8, 919-925. [CrossRef]

59. Cao, S.; Shao, Y.; Wang, Y.; Wu, T.; Zhang, L.; Huang, Y.; Zhang, F.; Liao, C.; He, J.; Wang, Y. Highly sensitive surface plasmon resonance biosensor based on a low-index polymer optical fiber. Opt. Express 2018, 26, 3988-3994. [CrossRef]

60. Dong, J.; Zhang, Y.; Wang, Y.; Yang, F.; Hu, S.; Chen, Y.; Zhu, W.; Qiu, W.; Guan, H.; Lu, H. Side-polished few-mode fiber based surface plasmon resonance biosensor. Opt. Express 2019, 27, 11348-11360. [CrossRef] [PubMed]

61. Zhang, R.; Pu, S.; Li, X. Gold-film-thickness dependent SPR refractive index and temperature sensing with hetero-core optical fiber structure. Sensors 2019, 19, 4345. [CrossRef] 
62. Cennamo, N.; Arcadio, F.; Minardo, A.; Montemurro, D.; Zeni, L. Experimental characterization of plasmonic sensors based on lab-built tapered plastic optical fibers. Appl. Sci. 2020, 10, 4389. [CrossRef]

63. Wang, G.; Li, Z.; Wang, J.; Shen, J.; Zhang, M.; Huang, M. Fabrication and sensing characterization of an S-tapered fiber probe. AIP Adv. 2020, 10, 075306. [CrossRef]

64. Wang, Q.; Jiang, X.; Niu, L.Y.; Fan, X.C. Enhanced sensitivity of bimetallic optical fiber SPR sensor based on MoS $_{2}$ nanosheets. Opt. Laser Eng. 2020, 128, 105997. [CrossRef]

65. Liu, L.; Deng, S.; Zheng, J.; Yuan, L.; Deng, H.; Teng, C. An enhanced plastic optical fiber-based surface plasmon resonance sensor with a double-sided polished structure. Sensors 2021, 21, 1516. [CrossRef] [PubMed] 